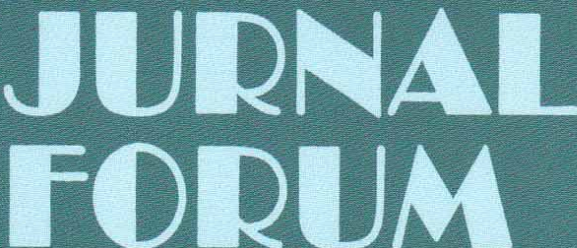

Volume 7 - Nomor 1

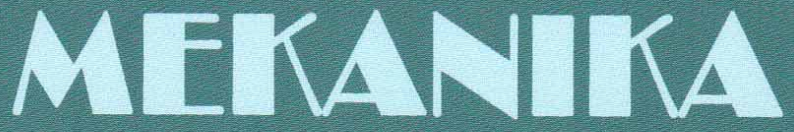

Mei 2018

ISSN : 2356-1491

PENGARUH FLY ASH DENGAN PENAMBAHAN CACAHAN KARET, SILICA FUME DAN SUPERPLASTICIZER TERHADAP BETON

TRI YUHANAH; TOMMY IDUWIN; BUDI WICAKSONO

PERILAKU STRUKTUR TOWER TRANSMISI TIPE SUSPENSION TERHADAP BEBAN ANGIN MUHAMMAD SOFYAN; DICKI DIAN PURNAMA; ABDUL ROKHMAN

IDENTIFIKASI PENYEBAB KECELAKAAN KERJA PADA PROYEK KONSTRUKSI BANGUNAN GEDUNG TINGGI

RETNA KRISTIANA; SLAMET

STUDI SIFAT MEKANIS TANAH MERAH DENGAN PENGUJIAN TRIAKSIAL REFFANDA KURNIAWAN RUSTAM

ANALISIS PENGARUH BESAR BUTIRAN AGREGAT KASAR TERHADAP KUAT TEKAN BETON NORMAL IKA SULIANTI; AMIRUDDIN; RIO SHAPUTRA; DARYOKO

ANALISIS BANJIR DAN TINGGI MUKA AIR PADA RUAS SUNGAI CILIWUNG STA 7+646 S/D STA $15+049$

IKA SARI DAMAYANTHI SEBAYANG; MELIANA PARLINA

ANALISIS KELAYAKAN PERENCANAAN PEMBANGUNAN JALAN PENGHUBUNG (MISSING LINK) ANTARA DESA SIKUR SAMPAI DESA PAOKMOTONG KABUPATEN LOMBOK TIMUR

DESSY ANGGA AFRIANTI; SIGIT IRFANSYAH; MEYRISSA PUTRI DEWANDARI 


\title{
STUDI SIFAT MEKANIS TANAH MERAH DENGAN PENGUJIAN TRIAKSIAL
}

\author{
REFFANDA KURNIAWAN RUSTAM \\ Jurusan Teknik, Sipil Fakultas Teknik, Universitas PGRI \\ E-mail : reffandakurniawan@yahoo.com
}

\begin{abstract}
Abstrak
Sifat tanah lunak dapat menyebabkan masalah ketidakstabilan dan penurunan jangka panjang. Hal ini dikarenakan tanah tersebut mempunyai nilai kuat geser tanah yang rendah dan kompresibilitas yang tinggi. Salah satu jenis tanah yang termasuk ke dalam jenis tanah lunak yaitu tanah lempung lunak. Tanah merah termasuk ke dalam jenis tanah lempung lunak. Oleh karena itulah tujuan penelitian ini untuk mengetahui parameter kuat geser tanah merah di daerah Pakjo Kota Palembang, Provinsi Sumatera Selatan. Alat yang digunakan untuk mendapatkan parameter sifat mekanis dari tanah merah dengan menggunakan alat Triaksial. Hasil indeks propertis tanah merah meliputi: nilai kadar air tanah asli $(\square 27,70 \%$, nilai berat jenis tanah $\left(G_{s}\right)$ 2,67, nilai batas cair $(L L)$ 66,00\%, nilai batas plastis $(P L)$ sebesar 25,13\% dan nilai indeks plastisitas (IP) sebesar 40,87\%. Klasifikasi tanah CH (USCS) dan A-7-6 (AASHTO). Hasil dari pengujian Triaksial UU yaitu nilai kohesi (c): 16,25-18,15 kPa. Hasil nilai sudut geser dalam (申):13,50 $14,75^{\circ}$. Hasil kuat geser $(\tau): 17,68-24,02 \mathrm{kPa}$. Nilai kuat geser tanah merah menunjukkan bahwa tanah tersebut termasuk tanah lunak $(12,5-25 \mathrm{kPa})$.
\end{abstract}

Kata Kunci : Tanah Merah, Triaksial, Kuat Geser

\section{Abstract}

Characteristics soft soil can cause instability and long-term degradation problems. This is because the soil has a low shear strength value and high compressibility. One type of soil belonging to the soft soil type is soft clay soil. Red soil belongs to the soft clay soil type. Therefore, the purpose of this research to determines the parameters of the shear strength of red soil in the area of Pakjo City Palembang, South Sumatra Province. The equipment had been used to obtain parameters of mechanical properties of red soil was using Triaxial apparatus. The results of the red soil properties index include: water content value $(\square .27 .70 \%$, specific gravity value (Gs) 2.67, liquid limit value (LL) $66.00 \%$, value of plastic limit of $25,13 \%$ and index value (IP) of $40.87 \%$ Classification of soil CH (USCS) and A-7-6 (AASHTO). The result of the Triaxial tests was the value of cohesion $(c): 16.25-18,15 \mathrm{kPa}$, and internal friction $(\square): 13.50-14.75^{\circ}$. The result of shear strength $(\square): 17.68-24.02 \mathrm{kPa}$. The shear strength value of red soil indicates soil which includes soft soil (12.5-25 $\mathrm{kPa})$.

Keyword : Red Soil, Triaxial, Shear Strength

\section{Latar Belakang}

Kekuatan geser tanah dapat didefinisikan sebagai kemampuan maksimum tanah untuk bertahan terhadap usaha perubahan bentuk pada kondisi tekanan dan kelembapan tertentu. Tanah merupakan komponen dasar yang mempunyai peranan penting dalam pekerjaan-pekerjaan sipil.

Salah satu jenis tanah yaitu tanah merah laterit yang terbentuk karena proses pelapukan batuan yang mengandung besi, ditandai dengan merahnya warna tanah.

Tanah laterit merupakan jenis tanah yang banyak mengalami pencucian oleh air hujan sehingga warnanya pucat dan kemerah-merahan atau kekuning-kuningan. Tanah ini memiliki kuat geser yang rendah, permeabilitas rendah dan proses konsolidasi yang lambat.
Jika suatu konstruksi dibangun di atas tanah lempung lunak maka dapat menyebabkan kerusakan-kerusakan seperti terangkatnya struktur plat, retakan pada perkerasan jalan dan jembatan, kerusakan jaringan pipa, longsoran, dan sebagainya. Sehingga perlu untuk mengetahui sifat-sifat dasar tanah tersebut seperti penyebaran ukuran butiran kemampuan mengalirkan air, sifat pemampatan bila dibebani, kapasitas daya dukung tanah terhadap beban dan kekuatan geser tanah.

Parameter kuat geser tanah dapat ditentukan dengan pengujian laboratorium terhadap sampel tanah asli. Pada penelitian ini bertujuan untuk mengetahui kuat geser tanah merah di daerah Pakjo kota Palembang, Provinsi Sumatera Selatan dengan menggunakan metode pengujian Triaksial. Melalui pengujian ini didapatkan hasil nilai kohesi dan sudut geser dalam. Nilai kohesi dan sudut geser dalam dapat digunakan untuk menyelesaikan 
masalah-masalah yang berhubungan dengan stabilitas massa tanah seperti kapasitas dukung pondasi, dinding penahan tanah dan stabilitas lereng.

\section{Landasan Teori}

Tanah didefinisikan oleh [1] sebagai material yang terdiri dari agregat mineral-mineral padat yang tidak tersementasi (terikat secara kimia) satu sama lain dan dari bahan-bahan organik telah melapuk (yang berpartikel padat) disertai dengan zat cair dan gas yang mengisi ruang-ruang kosong diantara partikel-partikel padat tersebut.

Tanah lempung merupakan jenis tanah yang berbutir halus yang mempunyai nilai daya dukung yang rendah dan sangat sensitif terhadap perubahan kadar air, yaitu mudah terjadi perubahan volume dan kembang susut. Tanah lempung merupakan agregat partikel-partikel berukuran mikroskopik dan submikroskopik yang berasal dari pembusukan kimiawi unsur-unsur penyusun batuan, dan bersifat plastis dalam selang kadar air sedang sampai luas. Tanah lempung merupakan deposit yang mempunyai partikel berukuran lebih kecil atau sama dengan $0,002 \mathrm{~mm}$ dalam jumlah lebih dari $50 \%[2,3]$.

Menurut [4], beberapa sifat yang dimilki tanah lempung yaitu ukuran butiran halus, kurang dari $0,002 \mathrm{~mm}$, permeabilitas rendah, kenaikan air kapiler tinggi, bersifat sangat kohesif, kadar kembang susut yang tinggi, dan proses konsolidasi lambat.

Tanah merah merupakan tipikal tanah residual yang mengalami kondisi pelapukan dan pencucian (leaching), hal ini berdampak pada kandungan Besi (Fe) dan alumunium oksida (Al oxides) yang menyebabkan tanah bewarna merah, karena itu tanah ini juga dapat disebut laterite. Tanah ini meliputi sebagian besar wilayah di Indonesia, pada tanah beriklim campuran basah dan kering, dan terbentuk dari batuan beku sedimen atau malihan.

Sistem klasifikasi dibuat untuk memberikan informasi tentang karakteristik dan sifat-sifat fisis tanah. Klasifikasi tanah juga berguna untuk studi yang lebih terperinci mengenai kepadatan tanah tersebut serta kebutuhan akan pengujian untuk menentukan sifat teknis tanah seperti karakteristik pemadatan, kekuatan tanah, berat isi dan sebagainya [3]. Adapun sistem klasifikasi tanah yang telah umum digunakan adalah Unified Soil Classification System (USCS) dan American Assosiation of State Highway and Transporting Official (AASHTO) $[5,6]$.

Sistem klasifikasi USCS merupakan system yang paling banyak digunakan. Percobaan yang dipakai adalah analisa butiran tanah dan batas cair serta batas plastis (batas-batas Atterberg). Semua tanah diberi dua huruf penunjuk berdasarkan hasil percobaan. Sistem ini mengelompokkan tanah ke dalam dua kelompok besar, yaitu tanah berbutir kasar dan tanah berbutir halus.

$$
\text { Pengklasifikasian sistem AASHTO }
$$

berdasarkan kriteria ukuran butir dan plastisitas. Maka dalam mengklasifikasikan tanah membutuhkan pengujian analisa butiran tanah dan batas-batas Atterberg. Sistem ini membedakan tanah dalam delapan kelompok yang diberi nama dari A-1 sampai A-8. A-8 adalah tanah organik yang bersifat tidak stabil sebagai bahan lapisan struktur jalan raya.

Kuat geser tanah ditentukan untuk mengukur kemampuan tanah menahan tekan tanpa terjadi keruntuhan. Seperti material teknik lainnya, tanah mengalami penyusutan volume jika menerima tekanan merata disekelilingnya. Apabila mengalami tegangan geser tanah akan mengalami distorsi dan apabila distorsi yang terjadi cukup besar, maka partikel partikelnya akan terpeleset satu sama lain dan tanah akan dikatakan gagal dalam geser. Dalam hampir semua jenis tanah daya dukungannya terhadap tekanan tarik sangat kecil atau bahkan tidak mampu sama sekali.

Tanah tidak berkohesi, kekuatan gesernya hanya terletak pada gesekan anatara butir tanah saja $(\mathrm{c}=0)$, sedangkan dengan tanah berkohesi dalam kondisi jenuh, maka $\square=0$ dan $\mathrm{S}=\mathrm{c}$. Parameter kuat geser tanah sangat diperlukan untuk analisa analisa daya dukung tanah, tegangan terhadap dinding penahan dan kestabilan lereng. Parameter

kuat geser tanah dapat diperoleh dengan pengujian di laboratorium, seperti: pengujian kuat tekan bebas, pengujian geser lengsung, dan pengujian Triaksial. Pada penelitian ini, pengujian yang dilakukan menggunakan pengujian Triaksial.

Pengujian Triaksial merupakan pengujian kuat geser yang sering di gunakan dan cocok untuk semua jenis tanah, terutama tanah lempung. Pada pengujian ini, kondisi pengaliran dapat di kontrol, tekanan air pori dapat di ukur, dan tanah jenuh dengan permeabilitas rendah dapat di buat konsolidasi. Masing-masing pengujian Triaksial memiliki spesifikasi yang disesuaikan dengan tipe konstruksi tertentu dan tidak semua jenis pengujian Triaksial sesuai untuk semua kondisi tersebut. Skema pengujian Triaksial terlihat pada Gambar 1 [7].

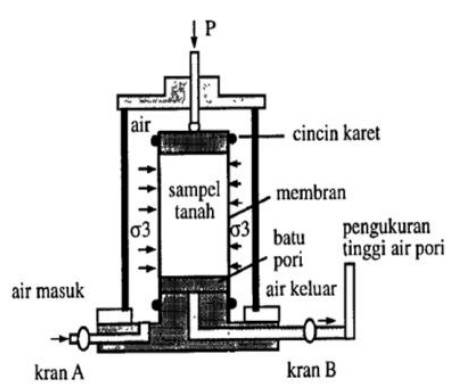

Gambar 1. Skema Pengujian Triaksial Sumber :Das (1995) 
Lingkaran Mohr digunakan untuk mencari parameter dari kekuatan geser tanah itu sendiri yaitu nilai kohesi $\left(\mathrm{C}_{\mathrm{u}}\right)$ dan sudut geser tanah $(\phi)$. Pada Gambar 2 dijelaskan bagaimana mendapatkan nilai kohesi dan sudut geser tanah yang digunakan sebagai parameter dari kuat geser tanah. Dalam rekayasa geoteknik istilah lunak dan sangat lunak khusus didefinisikan untuk lempung dengan kuat geser diperlihatkan pada Tabel 1 .

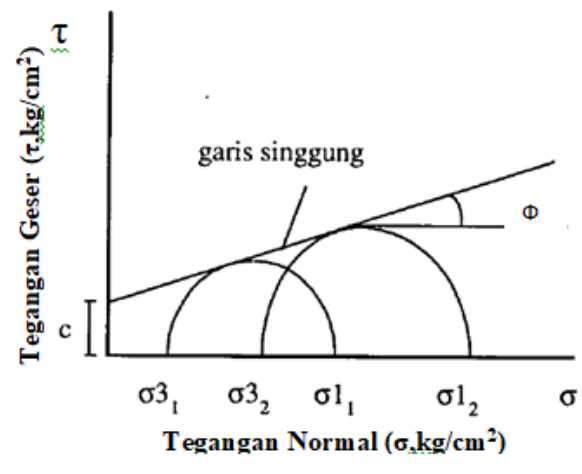

Gambar 2. Lingkaran Mohr Sumber :Das (1995)

Tabel 1. Nilai Kuat Geser

\begin{tabular}{|c|c|}
\hline Konsistensi & Kuat Geser $\left(\mathrm{KN} / \mathrm{M}^{2}\right)$ \\
\hline Lunak & $12,5-25$ \\
\hline Sangat Lunak & $<12,5$ \\
\hline \multicolumn{2}{|c|}{ Sumber :Departemen Kimpraswil (2002) }
\end{tabular}

Kekuatan geser tanah tak jenuh dapat dihitung dengan rumus :

$\tau=\mathrm{c}+(\sigma-\mathrm{u}) \tan \phi$

Dimana $\tau=$ kekuatan geser, $\sigma=$ tegangan total pada bidang geser, $\mathrm{u}=$ tegangan air pori, $\mathrm{c}=$ kohesi, $\phi=$ sudut geser

\section{Metodologi Penelitian}

Metode penelitian dimulai dengan melakukan studi literatur dengan mengkaji dan mempelajari buku-buku yang terkait dengan judul penelitian, jurnal ilmiah, penelitian terdahulu dan fasilitas internet lainnya yang berkaitan dengan tujuan dari penelitian. Kemudian dilanjutkan dengan pekerjaan lapangan yang meliputi: survei lokasi penelitian, pemilihan lokasi penelitian, dan persiapan alat dan material.

Pekerjaan survei lokasi penelitian yang dilakukan untuk menentukan lokasi pengambilan sampel. Adapun lokasi penelitian ini yaitu di daerah Pakjo Way Hitam Kota Palembang, Provinsi Sumatera Selatan. Selanjutnya mempersiapkan persiapan alat dan material yang diperlukan untuk pengambilan sampel, seperti: tabung sampel, kotak, lilin, tali, cangkul, dll).
Pengambilan sampel tanah terganggu dan tidak terganggu diambil pada kedalaman 0,5 m - 1 $\mathrm{m}$ [8]. Pengambilan sampel tanah terganggu digunakan untuk pengujian propertis tanah. Sedangkan pengambilan sampel tanah tidak terganggu dengan menggunakan bor (manual). Sampel tanah tak terganggu digunakan untuk pengujian Triaksial sebanyak 3 titik dengan 1 titik sebanyak 2 tabung sampel benda uji.

Pengujian yang dilakukan di laboratorium yaitu pengujian indeks propertis untuk mengetahui jenis tanah dan pengujian mekanikal untuk mengetahui parameter kuat geser tanah seperti nilai kohesi (c) serta sudut geser $(\varphi)$ tanah.

Pengujian propertis tanah meliputi: (a) pengujian kadar air $(\omega)$ menggunakan standar ASTM D-2216-80, (b) pengujian berat jenis butiran tanah $\left(\mathrm{G}_{\mathrm{S}}\right)$ menggunakan standar ASTM D-854-23, (c) pengujian batas-batas Atterberg. Ada dua jenis pengujian yaitu pengujian batas cair (LL) dan pengujian batas plastis (PL). Pengujian ini dilakukan dengan mengacu pada standar ASTM D422-63 dan ASTM D-424-74, (d) pengujian analisa saringan menggunakan standar ASTM D-421 dan ASTM D-422-72, [9] dan (e) Klasifikasi tanah menggunakan sistem Unified Soil Classification System (USCS) dan American Assosiation of State Highway and Transporting Official (AASHTO).

Setelah pengujian indeks propertis tanah dilakukan, maka tahap selanjutnya yaitu pengujian Triaksial (Gambar 4). Pengujian Triaksial dapat dilakukan dalam 3 keadaan yaitu UU (Unconsolidated Undrained), CU (Consolidated Undrained) dan CD (Consolidated Drained). Pada penelitian ini, Kondisi UU (Unconsolidated Undrained) digunakan untuk pengujian Triaksial pada tanah merah. Pengujian ini mengacu pada standar ASTM D 2850-70.

Kemudian dilanjutkan dengan menganalisa hasil yang diperoleh dari pengujian laboratorium baik itu pengujian indeks propertis maupun pengujian sifat mekanis tanah (pengujian Triaksial). Hasil pengujian propertis tanah digunakan untuk menentukan jenis tanah yang diuji. Pengujian Triaksial menghasilkan nilai kohesi (c) dan sudut geser dalam $(\phi)$. Kemudian nilai kohesi dan sudut geser dalam yang didapat dari pengujian digunakan untuk menghitung kuat geser tanah.

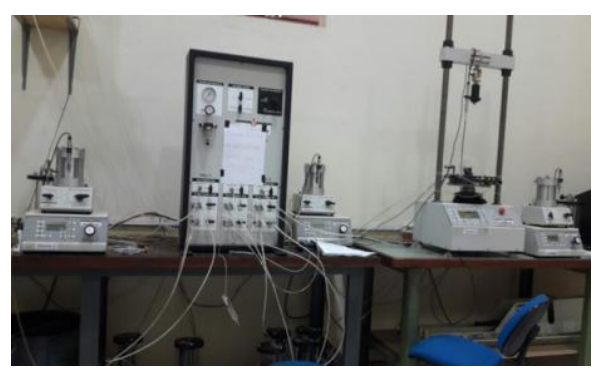

Gambar 3. Alat Pengujian Triaksial 


\section{Analisis Dan Pembahasan}

Pengujian tanah merah yang diambil dari daerah Pakjo Kota Palembang, Provinsi Sumatera Selatan dilakukan di laboratorium Mekanika Tanah Politeknik Sriwijaya Palembang. Adapun pengujian tersebut meliputi pengujian sifat fisis tanah (indeks propertis) dan pengujian sifat mekanis tanah. Pengujian indeks propertis seperti pengujian kadar air $(\omega)$, berat jenis (Gs), analisa butiran dan batasbatas Atterberg :batas cair (LL) dan batas plastis (PL).

Sedangkan pengujian mekanik yaitu pengujian Triaksial. Adapun hasil pengujian indeks propertis (kadar air, berat jenis, batas-batas Atterberg dan analisa saringan) serta klasifikasi tanah berdasarkan USCS (Unified Soil Classification System) dan AASHTO (American Assosiation of State Highway and Transporting Official) dapat dilihat pada Tabel 2.

Hasil dari Tabel 2 menunjukkan nilai kadar air tanah asli ( $\square$ ) sebesar 27,70, nilai berat jenis tanah $\left(G_{\mathrm{s}}\right)$ sebesar 2,67, nilai batas cair (LL, \%) sebesar 66,00, nilai batas plastis (PL, \%) sebesar 25,13 dan nilai indeks plastisitas (IP, \%) sebesar 40,87. Klasifikasi tanah yang diperoleh berdasarkan USCS (Unified Soil Classification System) adalah $\mathrm{CH}$ (tanah lempung). Sedangkan klasifikasi tanah menurut AASHTO (American Assosiation Of State Highway and Transporting Official) adalah A-7-6 (clavey soils).

Tabel 2. Hasil Pengujian Sifat Fisik

\begin{tabular}{|c|l|c|}
\hline No. & \multicolumn{1}{|c|}{ Jenis Pengujian Tanah } & Hasil \\
\hline 1. & Kadar air asli $(\omega, \%)$ & 27,70 \\
\hline 2. & Berat jenis tanah $\left(\mathrm{G}_{\mathrm{s}}\right)$ & 2,67 \\
\hline 3. & $\begin{array}{l}\text { Tanah lolos saringan No.4 }(0,425 \\
\mathrm{mm})(\%)\end{array}$ & 94,48 \\
\hline 4. & $\begin{array}{l}\text { Tanah lolos saringan No.200 }(0,075 \\
\text { mm) }(\%)\end{array}$ & 82,56 \\
\hline 5. & Batas Cair (LL) (\%) & 66,00 \\
\hline 6. & Batas Plastis (PL) $(\%)$ & 25,13 \\
\hline 7. & Indeks Plastis (IP) $(\%)$ & 40,87 \\
\hline 8. & Klasifikasi USCS & A-7-6 \\
\hline 9. & Klasifikasi AASHTO & \\
\hline
\end{tabular}

Pengujian sifat mekanis pada penelitian ini dilakukan dengan pengujian Triaksial pada tanah merah. Pengujian Triaksial bertujuan untuk mengetahui parameter kuat geser tanah, yaitu nilai kohesi (c) dan sudut geser dalam $(\varphi)$. Pengujian ini menggunakan program Humboldt Material Testing Software.

Satu lokasi pengambilan sampel tanah merah terdiri dari tiga (3) titik sehingga pada satu lokasi dilakukan 2 kali pengujian geser langsung. Jadi total pengujian geser langsung pada penelitian ini sebanyak 6 kali pengujian dengan total sampel benda uji 18 sampel. Dalam penelitian ini, pengujian Triaksial kondisi Unconsolidated Undrained (UU) dilakukan sebanyak 2 (dua) kali dengan menggunakan tegangan sel masing-masing sebesar $50 \mathrm{kPa}$ dan $100 \mathrm{kPa}$ pada setiap sampel yang diuji. Benda uji dibuat dengan menggunakan cetakan berbentuk silinder dengan tinggi $7 \mathrm{~cm}$ dan diameter $3,5 \mathrm{~cm}$.

Hasil pengujian Triaksial diperoleh data gaya geser, pergeseran horizontal, regangan dan tegangan geser. Semua data yang diperoleh tersebut terangkum dalam tabel data geser untuk setiap sampel tanah. Data hasil pengujian Triaksial tanah dianalisis untuk mendapatkan parameter kuat geser tanah. Tegangan geser dihitung dengan membagi nilai gaya geser dari pengujian Triaksial dengan luas sampel tanah.

Hasil pengujian Triaksial UU pada tanah merah dapat dilihat pada lingkaran Mohr dalam Gambar 4, Gambar 5, Gambar 6, Gambar 7, Gambar 8, dan Gambar 9. Dari gambar-gambar tesebut didapatkan parameter kohesi (c) dan sudut geser ( $\square$ ). Hasil nilai kohesi tanah (c) dan sudut geser dalam $(\phi)$ yang didapat dari pengujian Triaksial terangkum pada Tabel 3. Nilai kuat geser tanah dapat dihitung berdasarkan parameter nilai kohesi dan sudut geser dalam (rumus persamaan 1) dari hasil pengujian Triaksial. Adapun nilai parameter kuat geser tanah merah dapat dilihat di Tabel 4.

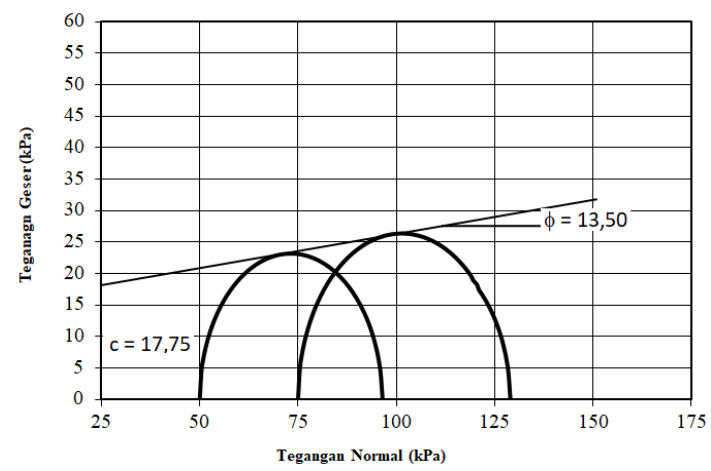

Gambar 4. Hasil Pengujian Triaksial Titik 1A

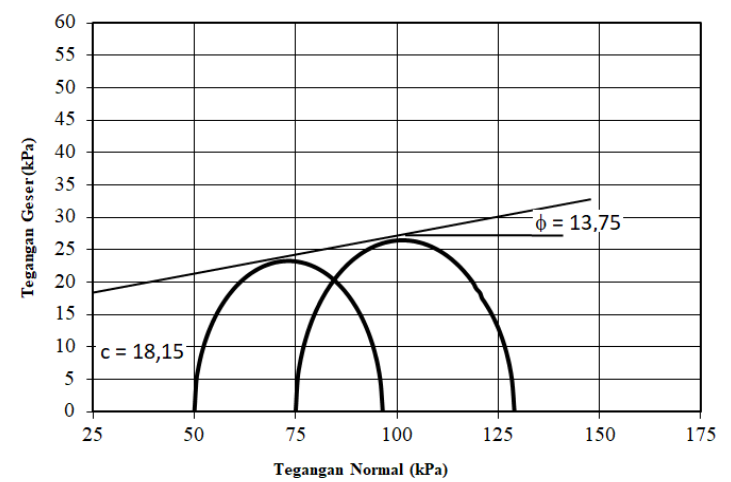

Gambar 5. Hasil Pengujian Triaksial Titik 1B 


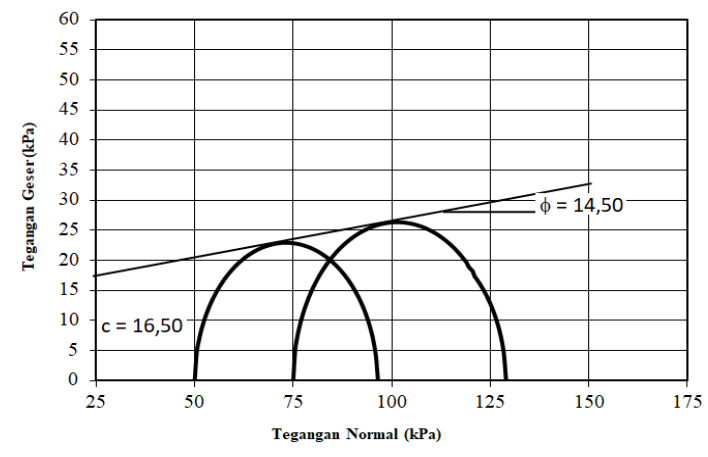

Gambar 6. Hasil Pengujian Triaksial Titik 2A

Berdasarkan Tabel 3, terlihat bahwa nilai kohesi (c, kPa) yang paling rendah sebesar 16,25 dan nilai kohesi (c, $\mathrm{kPa}$ ) yang paling besar sebesar 18,15 . Sedangkan hasil nilai sudut geser dalam $(\varphi$, $\left.{ }^{\circ}\right)$ yang paling rendah sebesar 13,50 dan nilai sudut geser dalam $\left(\varphi,{ }^{\circ}\right)$ yang paling besar sebesar 14,75 .

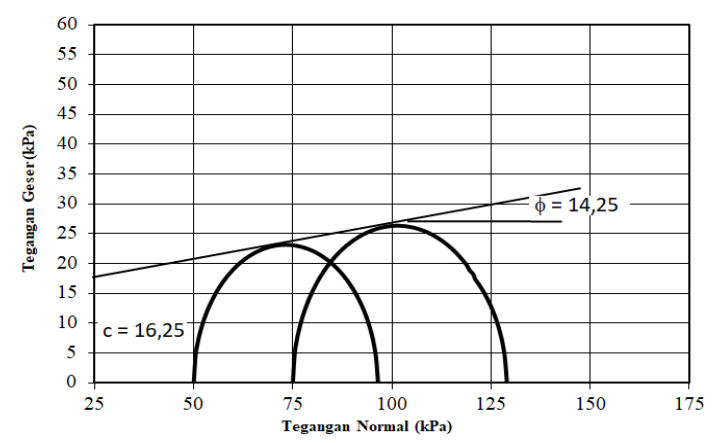

Gambar 7. Hasil Pengujian Triaksial Titik 2B

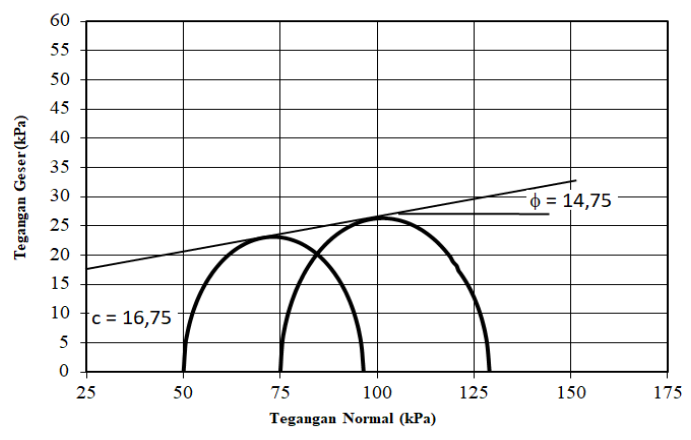

Gambar 8. Hasil Pengujian Triaksial Titik 3A

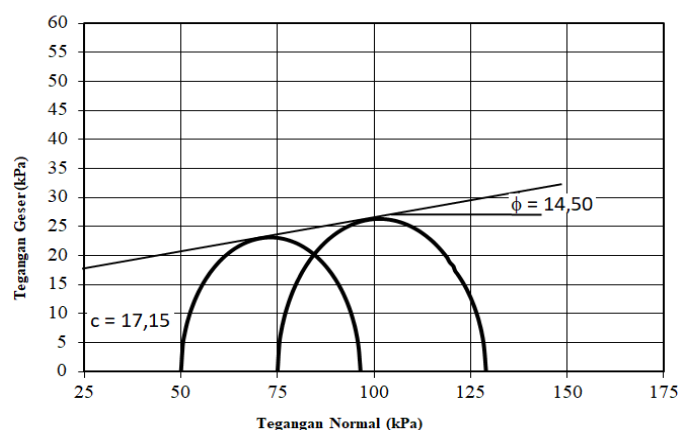

Gambar 9. Hasil Pengujian Triaksial Titik 3B
Tabel 4 menunjukkan hasil kuat geser $(\tau, \mathrm{kPa})$ tanah merah yang paling rendah sebesar 17,68 dan kuat geser $(\tau, \mathrm{kPa})$ tanah merah yang paling besar sebesar 24,02. Hasil nilai kuat geser tanah merah ini berdasarkan Tabel 1 termasuk dalam kategori tanah lunah. Range nilai kuat geser $(\tau, \mathrm{kPa})$ tanah lunak sebesar 12.50-25.00. Salah satu sifat dari tanah lunak yaitu nilai daya dukung yang rendah. Daya dukung tanah perlu diketahui untuk menghitung dan merencanakan dimensi podasi yang dapat mendukung beban struktur yang akan dibangun.

Tabel 3. Hasil Pengujian Triaksial UU (c dan $\varphi$ )

\begin{tabular}{|c|c|c|c|}
\hline \multicolumn{2}{|c|}{ Lokasi } & $\begin{array}{c}\text { Kohesi } \\
(\mathrm{c})(\mathrm{kPa})\end{array}$ & $\begin{array}{c}\text { Sudut Geser } \\
\text { Dalam }(\varphi)\left(^{\circ}\right)\end{array}$ \\
\hline \multirow{2}{*}{ Titik 1 } & A & 17,25 & 13,50 \\
\cline { 2 - 4 } & B & 18,15 & 13,75 \\
\hline \multirow{2}{*}{ Titik 2 } & A & 16,50 & 14,50 \\
\cline { 2 - 4 } & B & 16,25 & 14,25 \\
\hline \multirow{2}{*}{ Titik 3 } & A & 16,75 & 14,75 \\
\cline { 2 - 4 } & B & 17,15 & 14,50 \\
\hline
\end{tabular}

Tabel 4.Hasil Nilai Kuat Geser $(\tau)$ Tanah Merah

\begin{tabular}{|c|c|c|c|}
\hline \multicolumn{2}{|c|}{ Lokasi } & $\begin{array}{c}\text { Kuat Geser }(\tau) \\
(\mathrm{kPa})\end{array}$ & $\begin{array}{c}\text { Kuat Geser Rata-Rata } \\
(\tau)(\mathrm{kPa})\end{array}$ \\
\hline \multirow{2}{*}{ Titik 1 } & A & 24,02 & 23,40 \\
\cline { 2 - 3 } & B & 22,78 & \\
\hline \multirow{2}{*}{ Titik 2 } & A & 20,88 & \multirow{2}{*}{19,28} \\
\cline { 2 - 3 } & B & 17,68 & \multirow{2}{*}{22,43} \\
\hline \multirow{2}{*}{ Titik 3 } & A & 23,36 & \multirow{2}{*}{22,50} \\
\cline { 2 - 3 } & B & 21,50 & \multicolumn{2}{|c|}{} \\
\hline
\end{tabular}

Apabila daya dukung tanah rendah maka tanah tersebut tidak dapat menahan suatu beban yang bekerja padanya. Sehingga perbaikan tanah pada tanah merah yang telah diteliti perlu dilakukan apabila tanah merah tersebut akan digunakan sebagai tanah dasar.

\section{Kesimpulan}

Kesimpulan dalam penelitian ini yaitu dari hasil pengujian laboratorium memeprlihatkan bahwa tanah merah di daerah Pakjo Palembang Provinsi Sumatera Selatan memiliki nilai kadar air $(\square)$ sebesar 27,70 , berat jenis tanah $\left(G_{\mathrm{s}}\right)$ sebesar 2,67, batas cair (LL, \%) sebesar 66,00, batas plastis (PL, \%) sebesar 25,13 dan indeks plastisitas (IP, \%) sebesar 40,87. Berdasarkan sistem klasifikasi USCS termasuk kedalam klasifikasi tanah lempung atau $\mathrm{CH}$ dan berdasarkan system klasifikasi AASHTO adalah A-7-6 (clavey soils).

Hasil dari pengujian Triaksial UU yaitu nilai kohesi (c) yang paling rendah sebesar $16,25 \mathrm{kPa}$ dan nilai kohesi (c) yang paling besar sebesar 18,15 $\mathrm{kPa}$. Hasil nilai sudut geser dalam $(\varphi)$ yang paling rendah sebesar $13,50^{\circ}$ dan nilai sudut geser dalam $(\varphi)$ yang paling besar sebesar $14,75^{\circ}$. Serta Hasil 
kuat geser $(\tau)$ tanah merah yang paling rendah sebesar $17,68 \mathrm{kPa}$ dan kuat geser $(\tau)$ tanah merah yang paling besar sebesar $24,02 \mathrm{kPa}$.

\section{Ucapan Terima Kasih}

Penulis mengucapkan terima kasih kepada Hidayatullah yang telah membantu dalam penelitian ini.

\section{Daftar Pustaka}

[1] Das, Braja M. 1995. Mekanika Tanah 1. Erlangga, Jakarta

[2] Bowles, Joseph E. 1989. Sifat-Sifat Fisis dan Geoteknis Tanah Jilid 2. Erlangga, Jakarta.

[3] Bowles, Joseph E. 1991. Analisis dan Desain Pondasi Jilid-1. Erlangga, Jakarta.
[4] Hardiyatmo, Harry Christady. 2006. Teknik Pondasi I. PT Gramedia Pustaka Utama, Jakarta. Craig, R.F. 1989. Mekanika Tanah. Terjemahan oleh Budi Susilo Supanji. Erlangga, Jakarta.

[5] Darwawijaya, Isa. 1997. Klasifikasi Tanah . UGM Press, Yogyakarta.

[6] Craig, R.F. 1989. Mekanika Tanah. Terjemahan oleh Budi Susilo Supanji. Erlangga, Jakarta.

[7] Das, Braja M. 1995. Mekanika Tanah 1. Erlangga, Jakarta.

[8] Mustofa, Hasan. 1994. Teknik Sampling.

[9] American Society for Testing and Materials.1982. ASTM Book of Standards. Part 19, Phladelphia. 